\title{
Claim Your Space
}

This article is based on the Keynote address presented at the ACHPER (SA) \& SACPSSA Health and Physical Education 2017 Primary Years Conference.

Physical education has a long and valued history as an important contributor to primary school education in both Australia and New Zealand. It has played an integral part in the education of the "whole child" and has been valued by teachers, parents and students as offering an important and enjoyable contribution to their time at school.

It would be fair to say, however, that over recent years the levels confidence and certainty about the role of physical education in primary school educations has diminished. There have been a range of factors involved in this process including the increased emphasis on numeracy, literacy and STEM subjects and the subsequent positioning of these as more important than learning areas such as physical education, the social sciences and the arts. The expanding curriculum and the presence of sport based external providers, who are often perceived as "experts" within the school environment, have helped redefine physical education and the teaching and learning that occurs within the subject area.

This is perhaps an opportune time to step back a little, to reexamine and identify the contribution that physical education can make. Teachers are generally comfortable that regular physical education contributes towards improved skills, knowledge and understanding in the physical domain. There is a belief in physical education ability to help students understanding of the benefits of regular activity and to have some impact on students actual "fitness", and the various elements that are generally clustered under the broader term. There is also the perception in the wider community that physical education offers an opportunity for students to blow out the cobwebs, and that it is a release from the more important academic work of the classroom.

Because of the general awareness of the physical I will not dwell on the physical outcomes related to physical education. That is in no way to diminish the importance or centrality of the physical in physical education, it is our greatest strength and gives us the greatest opportunity to make an important contribution. I would suggest, however, that concentrating on the physical, limits physical education's "message" and contributes towards its feelings of being undervalued within education and society. This placing of the physical as subservient to the intellect is a well-established construct that remains largely unchallenged in modern western societies and is an issue I will return to later in the article.

There are many ways in which physical education can frame its contribution that will offer a wider view of the learning area. The first is in the broader conceptualization of wellbeing as conceptualized in the NZ curriculum (NZC, 2007). Total wellbeing is based on the Maori philosophy of Hauora, (figure 1) in which physical wellbeing, mental and emotional wellbeing, social wellbeing and spiritual wellbeing are each considered as one side of a foursided house (whare). For total wellbeing, all four sides of the house must be strong and work together to contribute towards stability. Hauora is an underpinning value of the NZ health and physical education learning area and as such offers both a challenge and opportunity to physical education to contribute to all aspects. Again, this is not to diminish the importance of the physical but to place it within the broader concept of total wellbeing. When considering the role of physical education in this broader concept the role of mental 
wellbeing is an interesting example. The epidemic of mental health issues occurring in schools and in wider society is an example of where physical education can play an important role. The benefits that regular physical activity play in helping alleviate anxiety and depression are well known and this reality could add another level of emphasis for many of the activities we currently teach. This role of mental wellbeing in the total wellness framework also leads physical education easily into teaching and learning around wellness based activities such as yoga, meditation and the mindfulness movement that is developing strongly around the world.

Insert Fig one near here

A second framework that has a natural alignment with physical education is that of social and emotional learning (SEL). SEL has been defined as "A process whereby youth develop knowledge and skills which they can use to interpret and control their emotions, build lasting friendships, develop strong social skills, identify and work towards personal goals and make healthy choices" (CASEL, 2014).

Within this broad definition sit five main areas.

- Self-management

The ability to successfully regulate one's emotions, thoughts, and behaviors in different situations.

- $\quad$ Self-awareness

The ability to accurately recognize one's own emotions and thoughts and how these influence behavior.

- Social awareness

The ability to take the perspective of and empathize with others, including those from diverse backgrounds and cultures.

- Relationship skills

Building relationships with diverse individuals and groups, communicating clearly, working cooperatively, resolving conflicts, asking for help.

- Responsible decision making

Considering the wellbeing of self and others, evaluating the realistic consequences of actions, making constructive safe choices for self, relationships and others.

The various elements of SEL are also obvious in the General Capabilities in the Australian Curriculum under personal and social capability, ethical understanding and intercultural understanding. In the New Zealand Curriculum they appear under the Key Competencies of managing self, relating to others and participating and contributing

SEL has become a central underpinning of many national curricula around the world including Australia and New Zealand. In many of these countries physical education has been the go-to learning area for exploring how SEL can be introduced and fostered within schools. While SEL offers obvious opportunities for framing physical education in a broader way the question is how does a quality physical education programme do this in practice? Can quality physical education strengthen and foster SEL and how can teachers maximize the learning in this area? 
One evaluation framework, SAFE, (sequential, active learning, focused and explicit) (Durlak, Weissberg \& Pachan, 2010) allows teachers to assess their programmes and to make appropriate adjustments as they are needed? SAFE was developed after a careful analysis of 69 empirical studies of successful positive youth development programmes and was designed to help teachers, and those working with youth, to evaluate whether their programmes were following best practice in Positive Youth Development. The authors concluded, after their analysis, that programmes that included all four aspects of SAFE were more successful in fostering the personal and social skills in participants than those that did not.

Teachers wishing to evaluate their programmes and teaching should identify whether they provide a coordinated (sequence) of activities that link the learning steps and provide students with opportunities to connect these steps. Is the learning (active), that is do students have the opportunity to practice these new behaviors and do they receive feedback on their performance. Is sufficient time and attention devoted to these values for learning to occur (Focus). Finally, are there clear and specific learning objectives rather than general ones (Explicit). Students need to know what they are expected to learn. Therefore, teachers need to identify explicitly what skills in these areas students are expected to learn (e.g., selfcontrol, problem-solving skills, resistance skills, and so on) (Durlak, Weissberg \& Pachan, 2010).

The message from the research that lead to the development of the SAFE framework is that Learning around SEL (or values) does not simply occur through participating in a physical education programme. There must be a commitment to their importance, followed by deliberate teaching to foster its development. If the commitment is there then an evaluation using the SAFE framework is a positive first stage. For teachers interested in looking to develop SEL in their physical education programmes the Teaching Personal and Social Responsibility (TPSR) model is also an option that should be considered. TPSR is specifically designed to facilitate the development of personal and social responsibility while still meeting the goals of the physical education curriculum. The TPSR Alliance website is a great first step for teachers interested in considering introducing this model into their teaching (http://www.tpsr-alliance.org).

TPSR is one of a number of models of teaching that are available for physical education teachers. Physical education is lucky that these models of practice are well researched, teacher tested and can be accessed reasonably easily. Many other learning areas do not have this advantage and we should make use of their availability. Along with TPSR three other well established models of practice are Sport Education, the variations of Teaching Games for Understanding and Cooperative Learning. All four are student centered models aligned with contemporary beliefs around best practice in education. While they have tended to be taught independently there is a great deal of potential in merged models which teachers should explore as they gain experience in the various approaches.

When promoting the benefits of quality physical education for our students it is important to be able to draw on research to back up our claims. One fascinating Australian based study used a quasi-experimental design over four years to examine the long-term impact of quality physical education on students. Thirteen intervention classes, received two 45-minute quality physical education classes a week, while 16 control classes received the "normal" physical education and sport programme. The findings from this study offer strong support for the value of quality physical education in primary schools. When examining health related outcomes, the study found that the students in the interventions classes had a lower risk of developing Type 2 diabetes, lower risk of developing $\mathrm{CV}$ disease and that there was 
favorable bone and heart remodeling in the girls. While these health-related outcomes could perhaps be expected through the enhanced levels of physical activity the impact on numeracy and literacy was also important. Principals and school leaders can resist allocating time for physical education because of the perceived need to concentrate on more academic areas. This study identified that students, who participated in regular quality physical education, scored higher in the NAPLAN assessments for numeracy and literacy than the equivalent students in the control classes. While physical educators can argue that happy, active kids receiving a well-rounded curriculum will do better in numeracy and literacy, this study offers strong empirical data to support the case. The value of quality physical education should not be equated with improvements in numeracy and literacy, however, it does no harm to have strong empirical evidence to negate the "we don't want to negatively impact on their academic progress" argument. The use of the "best evidence supports" approach can be particularly useful when talking to administrators and school leaders. There have been numerous publications from this study and teachers who are interested should google "LOOK Study", or approach their local ACHPER branch for more information.

As mentioned previously one of the problems for physical education is that we live in a world that largely privileges the intellect over the body. Historically there has been a view that the physical and intellect are separate with Descartes being generally credited with establishing the complete separation of the mind from the body. The situation now exists that, as Claxton (2015) described it, "there is a hegemony of the intellect (p. 4). We see it in the unthinking emphasis placed on numeracy and literacy as more important than other learning areas in the curriculum, and in the concentration on STEM subjects. As physical educators, we also buy into the belief when we parade the academic aspects of our subject as proof of our legitimacy. One development that directly challenges the hegemony of the intellect is that of embodied intelligence or embodied cognition. Guy Claxton (2015) in his book 'Intelligence in the Flesh (2017) described the body as:

....a massive steaming collection of interconnected communication systems that bind the muscle, the stomach, the heart, the senses and the brain so tightly together that no part - especially the brain - can be seen as functionally separate from, or senior to, any other part. (p.4)

Exploring the interconnectedness of the bodies systems and their impact on us as human beings is in many ways the new frontier and offers the opportunity to reexamine the contribution quality physical education can offer. While it is outside the scope of this article to explore this area in detail, readers who may like explore further will find Claxton's book is a useful starting point.

I started with the claim that it is time that physical education teachers "claimed their space". We must be confident in our unique contribution to the education of our students. We must not accept the narrative that in some way the academic (brain) centered learning is superior, or more important, than the embodied learning we facilitate as a natural part of our profession. But how do we do this?

Physical education teachers are often reluctant to talk the talk of education. Many of us have a well-established cynicism for those who use education speak, choosing to remove ourselves from the dialogue while complaining they don't take "us" seriously. If we wish to truly "claim our space" it is important we can talk the talk to those in power. When talking to principals or other school leaders, for example, if your programme has an explicit focus on social and emotional learning then describe the programme in these terms: 
In our programme we work hard to help the students identify their emotions and then to manage them. The physical environment gives numerous opportunities for us to identify when this is a problem and then we are quite explicit in addressing and facilitating their understandings around how they can develop the skills to address them.

I am not suggesting that you dress up your programmes in ways that are essentially dishonest. What I am saying is to have both the confidence to identify what you are doing well, in educational terms, and to talk articulately about then in appropriate contexts.

Don't justify your work through its impact on numeracy and literacy but mention the positive impact on them that quality physical education has. Share the data from the LOOK project with your leaders and other teachers. Use the "best evidence suggests that" phrase and back it up with empirical data.

If you have evaluated your programme using the SAFE framework, then tell people that: "we used a best evidence framework from the positive youth development literature to evaluate our programme. As a result, we have decided to place more focus on being explicit on the areas of SEL we want to foster.

At the risk of over emphasizing the point this is not a window dressing exercise. You need to be teaching quality physical education lessons. If you are simply rolling out the ball or running mini sport practices then you are not in a space where you can legitimately describe your lessons as educational or quality. In this case, it would be counterproductive to try to "sell" them as anything more than what they are. These types of "programmes" put the place of physical education at risk as they reinforce negative stereotypes and minimize the benefits that students gain from participation. I suspect also that the days whereby physical education could survive on the implicit understanding that kids need to blow out the cobwebs and its good for them to get outside are well and truly over.

We have a great deal to offer and quality physical education has enormous potential to contribute to the well-educated child. What we need to be doing is taking every opportunity to ensure children get the quality physical education programme they deserve, be very confident in its value both physically and in the broader context and take every opportunity to step up and claim our space as educators in, through and about the physical.

\section{References}

CASEL. (2014). What is social and emotional learning Retrieved from https://casel.squarespace.com/social-and-emotional-learning

Claxton, C. (2015). Intelligence in the flesh. Cornwell: Yale University Press

Durlak, J., Weissberg, R. \& Pachan, P. (2010). A meta-analysis of after-school programs that seek to promote personal and social skills in children and adolescents. American Journal of Community Psychology. 45, 294-309. DOI 10.1007/s10464-010-9300-6

The New Zealand Curriculum. (2007). Ministry of Education. Learning Media: Wellington:NZ.

Telford, R., Telford R., Olive, L. \& Cunningham, R.(2017). Look, Lifestyle Study. Retrieved from http://www.look.org.au/v2/ 
Figure 1

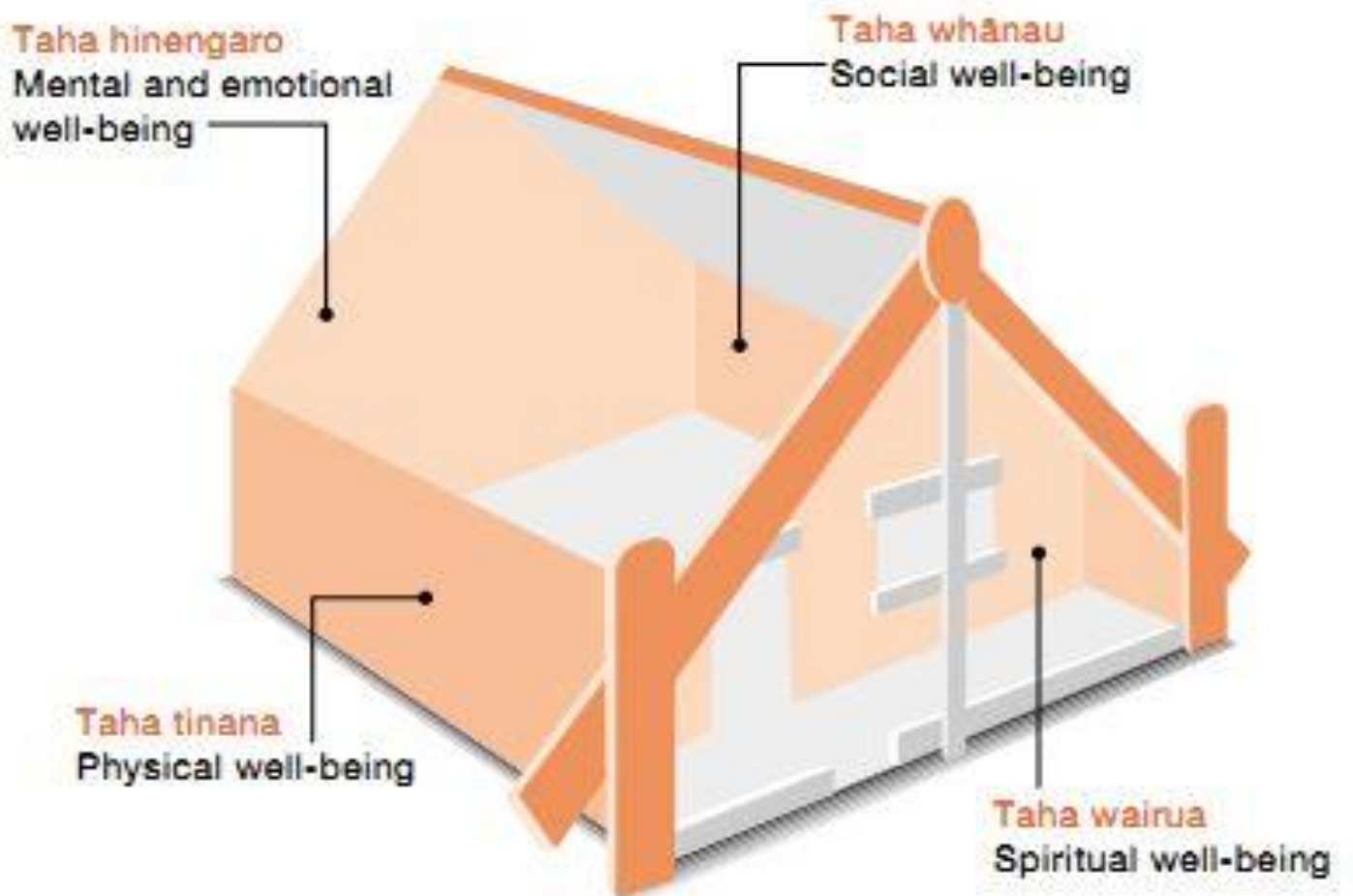

